\title{
EUROPEAN ROAD SAFETY POLICY BY 2020: A FORECAST ON TOPICS AND ACTIVITIES
}

\author{
Dr. Armin Kaltenegger \\ Austrian Road Safety Board (Kuratorium für Verkehrssicherheit - KFV) \\ Schleiergasse 18, 1100 Vienna, Austria \\ Phone: + 43577077 1200, E-mail: armin.kaltenegger@kfv.at
}

\section{INTRODUCTION}

25.500 people were killed on European roads in 2016. Thus, despite the achievements of the past, there is still need for action in order to reduce the number of injuries and fatalities in road traffic. Road safety will therefore certainly continue to be a part of the political agenda of the EU and its member states. However, the topics and activities of European road safety policy that will determine the next few years are less apparent, even though they have a strong impact on national policies. Official programmes usually provide an insight on a very general level only. For this reason, the Austrian Road Safety Board (KFV) has asked the Erfurt University of Applied Sciences to carry out an extensive policy analysis in order to forecast the topics and measures in EU policy up to 2020. The results are already available. For the presentation at the conference, they will be updated based on the developments up to May 2018, including a forecast on the next decade.

\section{OBJECTIVE}

The objective of the study was to create a clear picture of the future actions of the EU in terms of road safety policy. The forecast aims at supporting the work programmes of public and private institutions on both international and national level as well as important decision makers.

\section{METHOD}

The study focussed on EU politics while taking into account selected European countries with a comparatively high level of road safety, namely Sweden, Norway, Germany, and the United Kingdom. It is based on an evaluation of programmes, legal acts, and activities of the past years by the EU's institutions, national governments, and other public or private organisations. From these sources, the core documents were selected and analysed systematically in order to identify indicators of future developments. The findings were discussed with top representatives of the EU Parliament and Commission as well as national experts. Based on the results, conclusions were drawn on the activities and actions to be expected during the next years.

\section{RESULTS AND CONCLUSION}

The results were structured according to the seven objectives defined by the European Commission in its policy orientations on road safety 2011-2020. In the near future, the following developments can be expected on a European level:

- In the field of road safety education and driver education, the EU driving licence directive is being evaluated and amendments based on the results are to be expected. The European Commission has recently published a study on driver training, testing and medical fitness that 
recommends revising the driving licence directive and/or its annexes. Regarding the directive on initial qualification and periodic training for professional drivers, a proposal for a revision has already been published. The EU is also funding studies on driver distraction.

- Regarding enforcement, mainly recommendations are expected from the EU, particularly on the exchange of good-practice. The cross border enforcement directive has recently been evaluated, which could result in amendments. A study on the directive on the installation and use of speed limitation devices recommends extending the scope of the directive and equipping all vehicles for the transport of commercial goods with intelligent speed adaption systems. The Commission will probably consider this in the context of reviewing the general safety regulation which is currently carried out.

- In the area of road infrastructure both the infrastructure directive and the tunnel safety directive are currently revised. A roadmap has been published in June 2017, setting the objectives and time frame for the assessment of both directives. Proposals for amending the directives can be expected in 2018, with a possible extension to all highways as well as a focus on vulnerable road users and new technology (ITS).

- Technical vehicle safety and the promotion of the use of modern technology will gain more importance in the following years. A report on advanced vehicles safety features was published in December 2016. An impact assessment is carried out and a new proposal for the update of vehicle safety standards could be expected for early 2018. Also in 2018, new directives on technical vehicle inspection are going to be applied on a national level. A "road package" comprising several initiatives on competition in commercial road transport and other issues has been published in May 2017. C-ITS (cooperative ITS) will become a priority in the future: The industry stated its intention to introduce C-ITS enabled vehicles by 2019. Following a declaration by the European transport ministers urging the Commission to take further steps regarding the introduction of C-ITS, the Commission published a strategy in November 2016. According to this master plan, the framework for the deployment of networked vehicles should be set by 2019. A review of the ITS action plan and directive is also pending. A roadmap was published in March 2017, setting March 2018 as a completion date for the evaluation. As a first step, the period to adopt delegated legal acts, currently expiring on 26 August 2017, will be extended.

- The emergency call system eCall will contribute to the improvement of emergency services. A legislative initiative for a standardised platform could be published in the near future. An evaluation report assessing the achievements and penetration rate of eCall systems is expected in 2021. Additionally, emphasis is to be placed on seriously injured road users: It is estimated that around 135,000 people are seriously injured each year in the EU. After repeated requests both from NGOs and the EU Parliament, the Council of the EU finally set a target of 50\% reduction for the period 2020-2030 in June 2017.

- Regarding the protection of vulnerable road users, improvements to technical vehicle standards are being discussed. The safety of senior road users is a core field of action and subject of a research study that was published in 2016. However, no consensus among member states is expected on the question of medical tests for senior drivers. Further research findings from projects on vulnerable road users funded by the EU will be published within the next few years. 


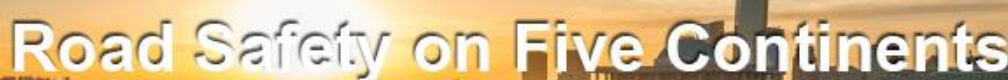 Jeju island, South Korea \\ May $16-18,2018$}

5. SUMMARY OF RESEARCH PROCESS AND RESULTS

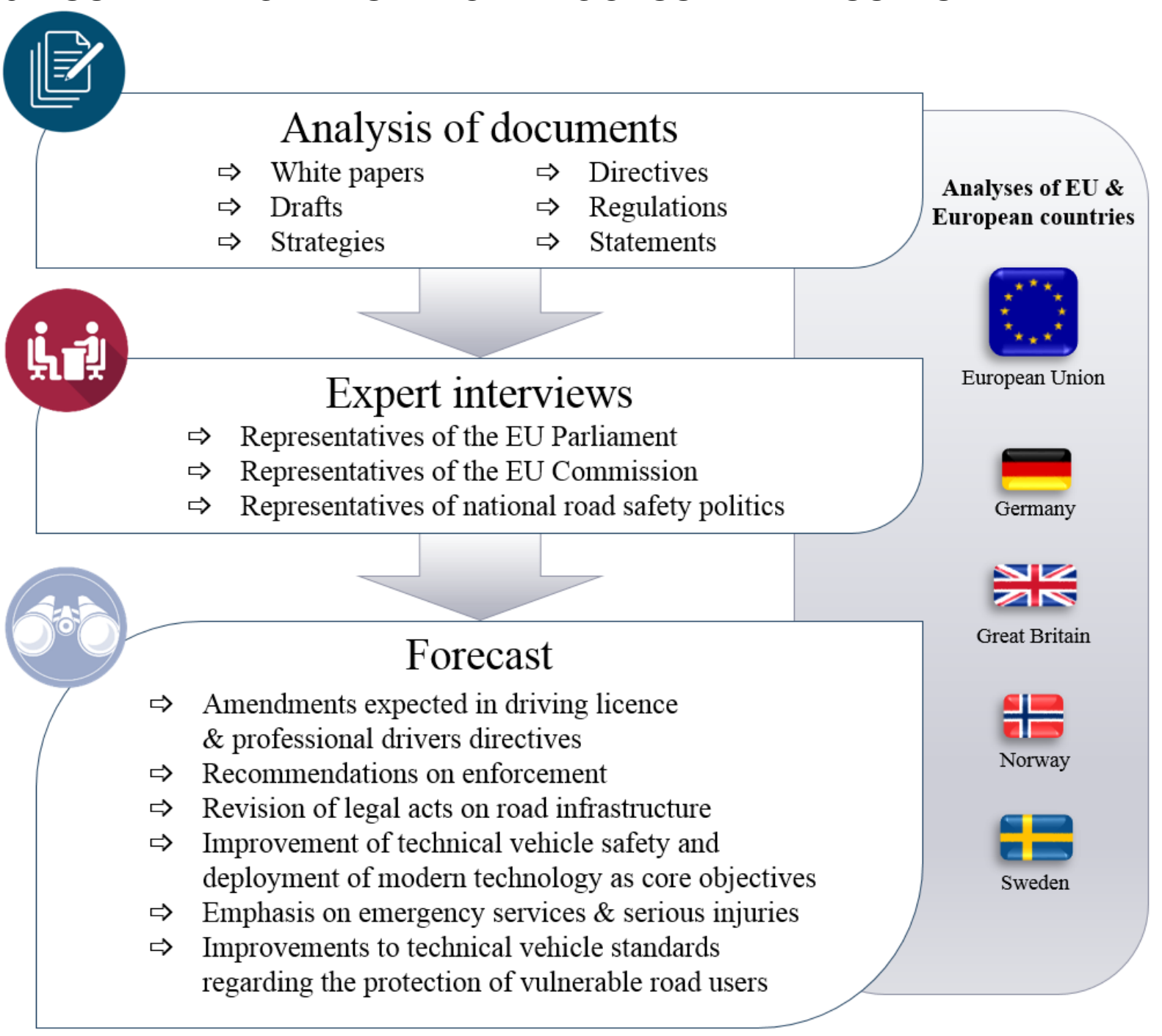

Figure 1 Graphic representation of research process and results.

The results show that the developments of the last years point towards a full and active road safety agenda for the future. Hopefully, the EU - though currently in a critical phase of defining the relation between pan-European and national interests - will be able to set milestones in road safety. This roadmap will support all stakeholders in road safety in their contribution to road safety policy during the next years. 